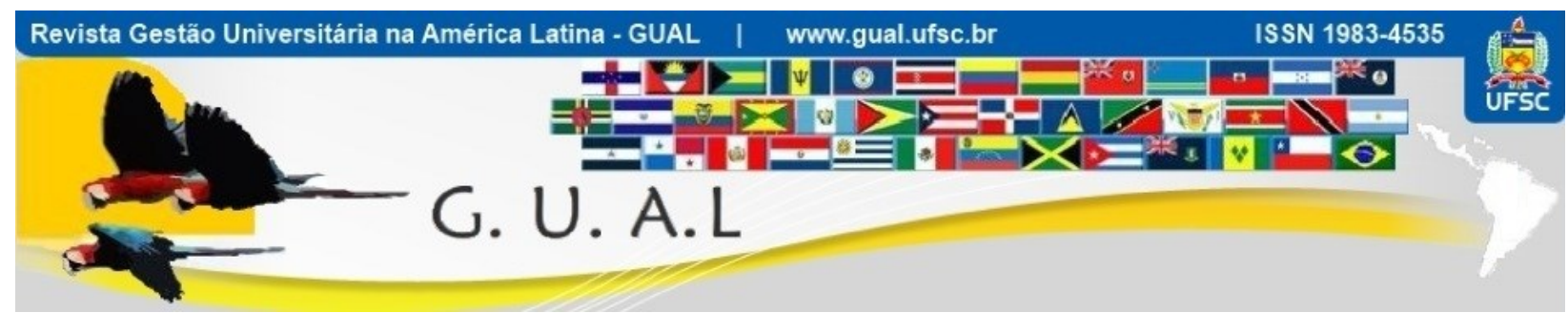

DOI: http://dx.doi.org/10.5007/1983-4535.2016v9n1p143

\title{
IMPACTO DO TREINAMENTO, COMPROMETIMENTO E ENTRINCHEIRAMENTO ORGANIZACIONAIS EM SERVIDORES DE UMA UNIVERSIDADE PÚBLICA
}

\author{
IMPACT OF TRAINING, ORGANIZACIONAL COMMITMENT \\ AND ENTRENCHMENT OF PUBLIC SERVANTS IN A PUBLIC UNIVERSITY
}

Laércio André Gassen Balsan, Doutorando

Universidade Federal de Santa Maria - UFSM laerciobalsan@yahoo.com.br

Luis Felipe Dias Lopes, Doutor Universidade Federal de Santa Maria - UFSM 1flopes67@yahoo.com.br

Juliano Nunes Alves, Doutorando Universidade Federal de Santa Maria - UFSM admjuliano@yahoo.com.br

Fernanda Binotto Vizzotto, Graduada Universidade Federal de Santa Maria - UFSM fevizzotto@yahoo.com.br

Vânia Medianeira Flores Costa, Doutora Universidade Federal de Santa Maria - UFSM vaniaflores2006@yahoo.com.br

Recebido em 08/abril/2014

Aprovado em 22/outubro/2015

Sistema de Avaliação: Double Blind Review

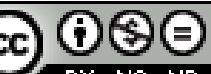

Esta obra está sob uma Licença Creative Commons Atribuição-Uso. 


\title{
RESUMO
}

Este trabalho foi desenvolvido com o propósito de investigar os níveis de impacto e suporte à transferência do treinamento, bem como os vínculos organizacionais estabelecidos por servidores públicos de uma Instituição Pública de Ensino Superior. Para tanto, realizou-se uma pesquisa descritiva de caráter quantitativo, valendo-se do estudo de caso. A amostra da pesquisa foi composta por 392 servidores de uma universidade federal. Os resultados demonstram que a amostra apresentou um alto impacto do treinamento no trabalho, um elevado comprometimento afetivo e um moderado entrincheiramento organizacional, indicando que os cursos realizados pelos servidores têm trazido retorno em termos de transferência e aplicação do conhecimento. Ainda, notou-se que a amostra pesquisada não pouparia esforços para atingir os objetivos institucionais, contrariando a imagem de baixo engajamento atribuída aos servidores públicos pela sociedade.

Palavras-chave: Comprometimento Organizacional. Entrincheiramento Organizacional. Suporte à Transferência de Treinamento. Impacto do Treinamento no Trabalho.

\begin{abstract}
This work was developed in order to investigate the levels of impact and support of training transfer and organizational ties established by public servants of a Public Institution of Higher Education. So, was performed a descriptive quantitative research, drawing on the case study. The survey sample consisted of 392 servers from a Federal Institution of Higher Education. The results show that the sample had a high impact on the job training, a high affective organizational commitment and a moderate entrenchment, indicating that courses provided by servers are brought back in terms of transfer and application of knowledge. Still, it was noted that the sample studied would spare no effort to achieve institutional goals, contradicting the image of low engagement assigned to them by society.
\end{abstract}

Keywords: Organizational Commitment. Organizational Entrenchment. Support of Training Transfer. Impact of Training on the Job. 


\section{INTRODUÇÃO}

Este trabalho foi desenvolvido com o propósito de investigar os níveis de impacto e suporte à transferência do treinamento, bem como os vínculos organizacionais estabelecidos por servidores públicos de uma Instituição Pública de Ensino Superior.

Após a publicação da lei 11.091/2005, que dispõe sobre a estruturação do Plano de Carreira dos Cargos Técnico-Administrativos em Educação no âmbito das Instituições Federais de Ensino vinculadas ao Ministério da Educação, que determina a obtenção do incentivo à qualificação do servidor que obtiver educação formal superior à exigida para o ingresso no cargo, tem-se notado uma grande procura por parte dos servidores TécnicoAdministrativos em Educação por cursos de graduação, pós-graduação, mestrado e doutorado. No entanto, desconhece-se como isso está impactando no setor de trabalho ou se esses servidores estão mais comprometidos e/ou entrincheirados com a organização.

Por esse motivo, a presente pesquisa foi realizada numa Instituição de Ensino Superior localizada na região central do estado do Rio Grande do Sul, que desempenha um papel fundamental na comunidade brasileira, pois dissemina conhecimento para todo o território nacional por meio do ensino, pesquisa e extensão (UFSM, 2009).

Este trabalho visa trazer importante contribuição para os órgãos públicos em geral, mas principalmente para as Instituições Públicas de Ensino Superior, as quais, conforme Brandão e Bastos (1993) têm sofrido fortes questionamentos sobre seu desempenho e papel social.

Finger e Brand (2001) complementam que o setor Público sofre pressões da sociedade, das empresas que querem se apropriar de uma fatia cada vez maior do mercado, e dos governantes, pois na concepção de muitos que estão alinhados à ideologia neoliberal, as privatizações parecem ser uma solução financeira (temporária); para outros, a desregulamentação é apenas um meio para introduzir competição, a qual, supostamente, aumenta a eficiência e a orientação aos usuários/clientes desses serviços.

Muitas são as pressões sofridas pelos órgãos públicos. Por isso da importância de se avaliar suas práticas. Nesse sentido, além de avaliar o Impacto da qualificação, buscou-se verificar os níveis de comprometimento e entrincheiramento organizacionais, os quais estão relacionados aos níveis de desempenho no trabalho, absenteísmo, rotatividade, bem estar e satisfação no trabalho (BASTOS et. al, 2009; RODRIGUES, 2009; BASTOS, 2013). 
Sabendo-se que o incentivo de qualificação previsto na lei 11.091/2005 onera os cofres públicos, chegou-se à seguinte inquietação: Quais são os níveis de impacto, suporte à transferência de treinamento, comprometimento e entrincheiramento organizacionais em servidores públicos que estão recebendo incentivo à qualificação devido à lei 11.091/2005?

Com base nessa problemática foram definidos os seguintes objetivos específicos que balizaram a realização deste estudo: (i) Identificar níveis de Impacto do treinamento no trabalho; (ii) Averiguar o nível de Suporte à transferência de treinamento; (iii) Verificar os níveis de Comprometimento e Entrincheiramento organizacionais.

\section{IMPACTO DO TREINAMENTO NO TRABALHO E TRANSFERÊNCIA DE TREINAMENTO.}

A avaliação dos treinamentos possibilita estabelecer a validade de um programa de capacitação por meio dos seus resultados no desempenho do empregado. O sucesso do treinamento deve propiciar ao empregado as habilidades exigidas pela tarefa, a fim de que esse alcance o desempenho desejado no trabalho. Entretanto, se não for feita uma avaliação, esses resultados não serão evidenciados (ALVES e TAMAYO, 1993).

O impacto do treinamento no trabalho é medido em termos da transferência e da influência do treinamento sobre o desempenho posterior do participante do treinamento (ABBAD, 1999). Desse modo, a autora conceitua transferência do treinamento como a aplicação correta no setor de trabalho dos conhecimentos, habilidades e atitudes aprendidas durante o processo instrutório.

Impacto do treinamento no trabalho é definido como a auto-avaliação feita pelo próprio participante acerca dos efeitos produzidos pelo treinamento em seus níveis de desempenho, motivação, autoconfiança e abertura às mudanças nos processos de trabalho (ABBAD, 1999).

Para se avaliar o Impacto do treinamento no trabalho deve-se levar em consideração outras variáveis. Abbad e Sallorenzo (2001) salientam que saber e querer fazer alguma coisa de modo eficaz ou inovador não são condições suficientes à transferência positiva de treinamento e de quaisquer outras formas de instrução, educação e formação de pessoal.

Abbad e Sallorenzo (2001) ressaltam que, nas abordagens tradicionais de avaliação de treinamento de Kirkpatrick (1976; 1977) e de Hamblin (1978), as variáveis-critérios reações, aprendizagem, desempenho no cargo e resultados mantêm entre si forte relacionamento positivo. As autoras, contudo, ressaltam que, de acordo com os estudos de Alliger e Janak 
(1989), esses relacionamentos nem sempre são significativos, pois os resultados de algumas pesquisas demonstram que, mesmo o participante tendo demonstrado satisfação e obtido boa pontuação na avaliação de aprendizagem, nem sempre aplica no trabalho suas novas habilidades adquiridas. Para Abbad e Sallorenzo (2001), isso ocorre não necessariamente por falta de memória ou deficiência no treinamento, mas porque faltaram oportunidades para colocar os conhecimentos adquiridos em prática.

Conforme Abdad e Salorenzo (2001), o conceito de suporte à transferência enfoca algumas condições necessárias à transferência positiva de aprendizagem e avalia o quanto essas estão presentes no ambiente de trabalho do aprendiz. Esse conceito envolve duas dimensões: o suporte psicossocial à transferência (inclui o apoio gerencial ao TD\&E (treinamento, desenvolvimento e educação)), os fatores situacionais de apoio e as conseqüências associadas ao uso dos CHAs (conhecimentos, habilidades e atitudes) adquiridos, e o suporte material. Apoio gerencial ao TD\&E é uma situação anterior ao TD\&E e relaciona-se ao apoio recebido pelo aprendiz para participar de todas as práticas de TD\&E. Fatores situacionais de apoio incluem o apoio gerencial, social dos pares e organizacional que o aprendiz recebe para aplicar no trabalho os CHAs adquiridos durante o TD\&E; apoio recebido pela chefia imediata, na remoção de eventuais obstáculos à transferência de aprendizagem, e acesso às informações necessárias para a aplicação dos novos conhecimentos no ambiente de trabalho. Consequências associadas ao uso de novos CHAs referem-se ao aparecimento de reações favoráveis ou desfavoráveis de colegas, superiores hierárquicos, diante a tentativa do funcionário em aplicar os novos CHAs adquiridos. Suporte material evidencia a qualidade, quantidade e disponibilidade de recursos materiais e financeiros, assim como a adequação do local de trabalho para a aplicação dos novos CHAs, contribuindo para o sucesso dos programas de treinamento (ABBAD; BORGES-ANDRADE, 2004).

\section{OS VÍNCULOS ORGANIZACIONAIS}

Ao longo de sua vida, o indivíduo desenvolve diversos vínculos com pessoas, grupos e organizações, um desses vínculos é o comprometimento organizacional (BASTOS et al., 2008; RODRIGUES, 2009; KLEIN; MOLLOY; BRINSFIELD, 2012).

Observa-se que esse vínculo é benéfico tanto para a organização como para o empregado comprometido, pois o conceito de comprometimento organizacional está ligado ao bem estar no trabalho e com a satisfação com o mesmo (FERRAZ e SIQUEIRA, 2006). 
Compreender essa relação que se estabelece com a organização proporcionaria o entendimento das diferentes atitudes e comportamentos tomados pelos indivíduos (SIQUEIRA e GOMIDE Jr., 2004). Isso possibilita um melhor esclarecimento da natureza dos processos psicológicos pelos quais as pessoas escolhem identificar-se com os objetivos da organização e a forma com que lhe atribuem significado (TEIXEIRA, 1994), a fim de se predizer comportamentos relevantes para o contexto organizacional (COHEN, 2003), tais como: o absenteísmo, a rotatividade e o desempenho (SIQUEIRA e GOMIDE Jr., 2004).

Mesmo que só o comprometimento organizacional não garanta o sucesso e o alcance dos objetivos de uma empresa, Muller et al. (2005) advogam que um funcionário comprometido se esforçará mais para atingir os objetivos da organização.

Para Mowday et al. (1979, p. 225), comprometimento organizacional é "um estado no qual um indivíduo se identifica com uma organização particular e com seus objetivos, desejando manter-se afiliado a ela com vistas a realizar tais objetivos". Assim sendo, comprometimento seria o grau de envolvimento com uma determinada organização (MOWDAY et al., 1982).

Outro vínculo estabelecido entre o indivíduo e a organização é o entrincheiramento organizacional. Rodrigues (2009) construiu um quadro teórico no intuito de definir esse construto, o qual foi criado com base no construto "entrincheiramento na carreira" proposto por Carson et al. (1995) e seus fatores, e em investigações anteriores na seara das organizações, que englobam as bases para o entrincheiramento propostas por Mowday et al. (1982) e a teoria dos side bets de Becker (1960).

Rodrigues (2009) e Bastos et al. (2013) salientam que o profissional entrincheirado permanece na organização por necessidade e não por querer, por gostar. O indivíduo projeta na empresa um meio de se proteger, de se sentir seguro, pois possui estabilidade e status social. Dessa forma, o trabalhador entrincheirado pressente que sua saída da organização lhe causará graves danos, e por isso permanece trabalhando, e não pelo fato de desejar contribuir para o crescimento da empresa.

É relevante estudar o motivo de o profissional tornar-se ou manter-se entrincheirado, pois essas motivações implicam algumas consequências negativas para a organização, uma vez que indivíduos entrincheirados e descontentes com seu trabalho não contribuem, não se esforçam, não estão engajados nos projetos da empresa para a qual trabalham, podendo comprometer o crescimento e os rendimentos da empresa (CARSON et al., 1995). 
A essência do vínculo de entrincheiramento envolve o sentimento do trabalhador de estar preso na organização por não conseguir visualizar uma alternativa que o sustente de acordo com suas necessidades e expectativas (BASTOS et al., 2013). Foi definido por Rodrigues (2009) e Rodrigues e Bastos (2012) como a tendência de um profissional a continuar em seu trabalho devido aos investimentos realizados, aos custos emocionais associados à mudança e à sensação de haver escassas opções fora de sua área de atuação. $\mathrm{O}$ indivíduo tende a não mudar de emprego pelo receio de ser estigmatizado devido ao seu afastamento, o medo de perder seu prestígio profissional, de reduzir seu salário após o afastamento e até mesmo pelas dificuldades associadas às limitações de empregabilidade.

\section{MÉTODO}

No intuito de atender aos objetivos delineados nesse estudo, realizou-se uma pesquisa descritiva explicativa, de caráter quantitativo. No que se refere à estratégia de pesquisa, utilizou-se o estudo de caso, o qual, de acordo com Gil (2010), permite uma análise profunda e exaustiva de determinado fato ou fenômeno.

A organização escolhida para a realização desse estudo foi a Universidade Federal de Santa Maria (UFSM) por se tratar de uma Instituição Pública de grande importância para a região onde está situada e também pelo papel social que desempenha.

A amostra deste estudo foi composta por 392 servidores técnico-administrativos da UFSM que possuíam curso superior à exigência do cargo (Graduação, Especialização, Mestrado ou Doutorado) e, consequentemente, estavam recebendo incentivo à qualificação. $\mathrm{O}$ cálculo amostral foi significativo a um nível de confiança de $95 \%$ e o erro amostral de 3,1\%.

Para a coleta de dados foi utilizado um questionário constituído por itens fechados. A primeira parte, denominada dados de identificação, é composta de treze questões com objetivo de idade, sexo, escolaridade, ano de início e conclusão do curso, estado civil, cargo, período de atuação na organização, se exerce cargo de chefia, cargo que ocupa ou que já ocupou, em quantos setores já trabalhou, qual a sua formação.

A segunda parte do questionário é constituída pelo questionário de auto-avaliação de Impacto do Treinamento no Trabalho (IMTT), que é constituído de quatro partes, quais sejam: (1) Impacto do Treinamento no Trabalho; (2) Fatores Situacionais de Apoio; (3) Suporte Material; e (4) Consequências Associadas ao Uso das Novas Habilidades. As três últimas partes pertencem à categoria denominada Suporte à Transferência. $\mathrm{O}$ fator único impacto do 
treinamento no trabalho contém 12 itens, e expressa a percepção do participante sobre os efeitos exercidos pelo treinamento no próprio desempenho e motivação no trabalho (ABBAD, 1999).

Todos esses itens estão associados a uma escala Likert de cinco pontos: nunca, raras vezes, algumas vezes, frequentemente e sempre. São nove afirmativas referentes a "Fatores Situacionais de Apoio", as quais permitiram ao participante avaliar o apoio gerencial, social (do grupo de trabalho) ou organizacional à transferência de treinamento. $\mathrm{O}$ conjunto de afirmativas "Suporte Material" contém seis itens que se referem à qualidade, suficiência e disponibilidade de recursos materiais e financeiros, assim como à adequação do ambiente físico do local de trabalho à transferência de treinamento. O conjunto de afirmativas relativas às "Conseqüências Associadas ao Uso de Novas Habilidades" é composto de sete itens que se referem à opinião do participante do treinamento acerca da ocorrência de reações favoráveis ou desfavoráveis dos colegas à transferência de treinamento (ABBAD, 1999).

As respostas dos participantes foram analisadas como variáveis componentes da versão reduzida, do modelo IMPACT - Modelo Integrado de Avaliação do Impacto do Treinamento no Trabalho (ABBAD, 1999). A terceira e última parte do questionário, denominada Comprometimento e Entrincheiramento, foi constituída pelo modelo de avaliação de Comprometimento Organizacional de três fatores (BASTOS et al, 2009) e Entrincheiramento Organizacional (RODRIGUES, 2009; RODRIGUES e BASTOS, 2012).

Para a medição do nível de concordância com as afirmativas desta parte do questionário, foi utilizada uma escala do tipo Likert, de cinco pontos, onde a atribuição do número 1 representa "Nunca" e o número 5, "Sempre", para a escala de suporte à transferência de treinamento; e, onde a atribuição do número 1 representa "Discordo totalmente" e o número 5, "Concordo Totalmente", para a avaliação do comprometimento e entrincheiramento organizacionais.

A situação planejada para a coleta de dados consistia na aplicação do questionário na situação de trabalho. Os instrumentos foram entregues pessoalmente aos sujeitos que aceitavam participar da pesquisa, momento no qual recebiam uma explanação sobre os objetivos do estudo, sobre as normas éticas, sobre a confidencialidade dos dados, o tratamento de dados e a disponibilidade dos resultados. Juntamente com os questionários, os indivíduos interessados em participar da pesquisa recebiam um Termo de Consentimento Livre e Esclarecido (TCLE), o qual era assinado e preenchido pelo participante. 
Os dados obtidos por meio dos questionários foram quantitativamente analisados, por meio do software "SAS, versão 9.1”. Inicialmente, realizaram-se análises descritivas (de tendência central e de dispersão) e exploratórias para investigar a exatidão da entrada dos dados; a distribuição dos casos omissos; o tamanho e a descrição da amostra. Posteriormente, utilizou-se o indicador de consistência interna Alpha de Cronbach, com o propósito de verificar a confiabilidade dos construtos teóricos utilizados no questionário.

Para identificar os níveis de comprometimento, entrincheiramento, suporte à transferência e impacto do treinamento no trabalho resultantes das respostas de cada indivíduo, os dados intervalares foram transformados em dados categóricos. A categorização dos dados levou em conta o cálculo da média das respostas dos indivíduos em relação à escala Likert de 5 pontos utilizada no questionário. De posse das médias de cada construto, as mesmas foram arredondadas para números inteiros. Assim, convencionaram-se três categorias distintas (Baixo, Moderado e Alto) para cada variável, conforme descrito no Quadro 1.

\begin{tabular}{|c|c|l|}
\hline Média obtida & Categorias & \multicolumn{1}{c|}{ Variável } \\
\hline 1 e 2 & Baixo & $\begin{array}{l}\bullet \text { Comprometimento } \\
\bullet \text { Entrincheiramento } \\
\bullet \text { Suporte à transferência } \\
\bullet \text { Impacto do treinamento no trabalho }\end{array}$ \\
\hline 3 & Moderado & $\begin{array}{l}\bullet \text { Comprometimento } \\
\bullet \text { Entrincheiramento } \\
\bullet \text { Suporte à transferência } \\
- \text { Impacto do treinamento no trabalho }\end{array}$ \\
\hline 4 e 5 & Alto & $\begin{array}{l}\bullet \text { Comprometimento } \\
\bullet \text { Entrincheiramento } \\
\bullet \text { Suporte à transferência } \\
- \text { Impacto do treinamento no trabalho }\end{array}$ \\
\hline
\end{tabular}

Quadro 1 Convenção das categorias.

Fonte: Elaborado pelo autor.

Os fatores de comprometimento (afetivo, instrumental e normativo), de entrincheiramento (ajustamento à posição social, limitações de alternativas e arranjos burocráticos) e as categorias de suporte à transferência (fatores situacionais de apoio, suporte material e consequências associadas ao uso de novas habilidades) também seguiram essa convenção. 


\section{ANÁLISE DOS RESULTADOS}

Em relação ao perfil da amostra, observou-se um ligeiro predomínio do sexo feminino (58,06\%), vindo ao encontro do entendimento de Bastos (1994), que afirma ser amplo o predomínio de mulheres na administração pública. Com relação à escolaridade, parte da amostra possui ao menos graduação $(25,06 \%)$; a grande maioria possui especialização $(56,01 \%)$, constituindo mais da metade da amostra; poucos indivíduos possuem mestrado $(16,11 \%)$ e uma pequena parcela possui doutorado (2,56\%). A amostra foi bastante diversificada quanto à idade (média em torno de 44 anos) e tempo de serviço na organização (média de 17 anos). Aproximadamente 35\% dos entrevistados ocupavam cargos de chefia no momento da pesquisa.

Na Figura 1 são apresentadas as médias arredondadas das variáveis do estudo dentro de uma escala Likert de 5 pontos (eixo Y). Essa escala está dividida em três categorias: Baixo (média 1 e 2), Moderado (média igual a 3) e Alto (média 4 e 5), com a finalidade de melhor esclarecer o nível atingido por cada variável (representadas no eixo X).

As médias de Comprometimento Organizacional demonstram que os servidores apresentam um vínculo afetivo e instrumental maior (alto) do que o vínculo normativo (baixo). As médias de Entrincheiramento Organizacional não apresentaram diferenças significativas entre Ajustamento às Posições Iniciais e Limitações de Alternativas, ressaltando que os servidores percebem como alto os aspectos referentes aos Arranjos Burocráticos Impessoais. Com relação ao impacto do treinamento no trabalho, os servidores apresentaram um impacto do treinamento no trabalho alto (média arredondada igual a 4), mesmo com um suporte à transferência do treinamento moderado (média arredondada igual a 3). Ressalta-se que o sucesso da aprendizagem e do impacto do treinamento no ambiente de trabalho depende de recursos materiais apropriados e da existência de apoio da chefia e da própria organização (ABBAD e BORGES-ANDRADE, 2004). De acordo com Abbad (1999), as principais variáveis preditoras de Impacto do Treinamento no Trabalho pertencem aos componentes de Suporte à Transferência. 


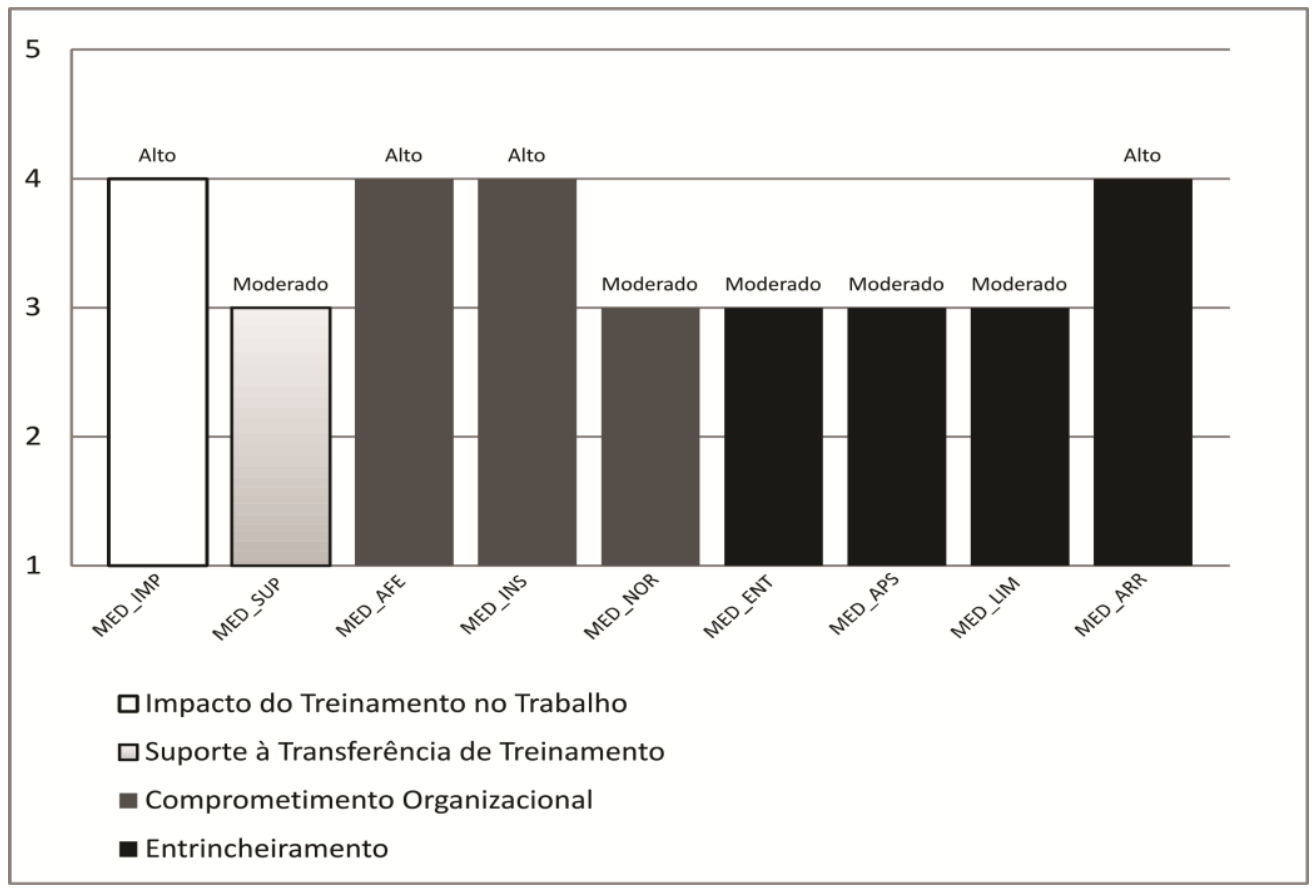

Figura 1 Médias gerais dos construtos.

Fonte: Dados da pesquisa.

*MED_IMP = Média do Impacto do Treinamento no Trabalho; MED_SUP = Média do Suporte à Transferência de Treinamento; MED_AFE = Média do Comprometimento Âfetivo; MED_INS = Média do Comprometimento Instrumental; MED_NOR = Média do Comprometimento Normativo; MĒD_ENT = Média Geral do Entrincheiramento; MED_APS = Média do Fator Ajustamento à Posição Social; MED_LIM = Média do Fator Limitações de Alternativas; MED_ARR = Média do Fator Arranjos Burocráticos Impessoais.

Pesquisas como a de Rowe e Bastos (2008) também demonstraram um forte vínculo afetivo em instituições públicas. Outro estudo (Brandão e Bastos, 1993), mais específico com uma instituição pública universitária, também apontou que o componente afetivo do funcionário público se mostrou bastante presente, o que foi revelado pelo desejo de permanecer na organização e de contribuir para com esta.

Por meio das frequências, pode-se observar que a grande maioria da amostra ( $85 \%)$ apresentou um impacto no treinamento no trabalho alto, $12 \%$ um impacto moderado e apenas $3 \%$ da amostra perceberam seu impacto como sendo baixo. Com base nesses resultados, verifica-se um impacto positivo nas atividades desempenhadas pelos servidores após a realização dos seus cursos, o que indica que os cursos realizados pelos servidores contribuíram para uma maior eficiência no setor de trabalho.

A maior parte dos consultados concordou que, após seus cursos, encontra-se mais motivado e autoconfiante no trabalho, respectivamente. De modo geral, os desvios-padrão foram baixos, o que indica pouca variabilidade de respostas entre os pesquisados. Esse fato 
reforça a avaliação favorável obtida dos indivíduos em relação ao nível de impacto do treinamento no trabalho.

Os participantes dos cursos tiveram sua autoconfiança aumentada em relação a sua capacidade de execução das tarefas e aproveitaram as oportunidades de colocar em prática o que foi aprendido, assim como obtiveram maior motivação para o trabalho. Observou-se ainda que os participantes da pesquisa não diminuíram o número de erros no setor de serviço. Esse fato pode ser explicado pela estandardização dos processos e atrelamento às normas dentro de um contexto extremamente burocrático.

Quanto ao Suporte à Transferência de Treinamento, ficou evidenciado que mais da metade dos indivíduos, ou seja, $64 \%$ apresentaram um suporte à transferência do treinamento moderado, $25 \%$ um suporte alto e $11 \%$ perceberam o suporte como sendo baixo.

Ao analisar cada categoria separadamente, nota-se que $22 \%$ da amostra foi desfavorável aos fatores situacionais de apoio. Ainda, encontrou-se um número expressivo (50\%) de participantes concordando que, em seu ambiente de trabalho, o servidor "algumas vezes" recebe o apoio gerencial, social e institucional para transferir as novas habilidades aprendidas durante o curso.

Observa-se que as habilidades adquiridas pelos servidores durante seus cursos apresentarão efeitos mais positivos se houver um clima favorável. Não basta garantir o comprometimento das chefias com o levantamento de necessidades, é preciso dar o apoio à participação nas aulas e o encorajamento do subordinado a aplicar no trabalho as novas habilidades, como sugerem Broad (1982), Coffman (1990), Feldman (1981), Georgenson (1982) e Melissa e Newstrom (1980). É necessário que a organização, chefes, pares e colegas propiciem o Suporte à Transferência para que o indivíduo possa aplicar os CHAs aprendidos durante os cursos (ABBAD, 1999).

Quanto ao "Suporte Material", quase a metade da amostra (48\% dos consultados) definiu como "frequentemente" ou "sempre" recebem materiais suficientes e de qualidade para aplicação das novas competências, 39\% indicaram que recebem um suporte material moderado, e a minoria (13\%), um suporte material baixo. No estudo feito por Abbad (1999), as opiniões da maior parte dos consultados, em relação ao Suporte Material à transferência, também foram, de modo geral, favoráveis.

No que concerne às "Consequências Associadas ao Uso das Novas Habilidades", 15\% da amostra recebe reações favoráveis diante das tentativas de aplicar no trabalho as novas 
habilidades que aprendeu durante seu curso; 13\% "nunca" ou "raras vezes" recebem e a grande maioria da amostra (72\%) recebe apoio apenas "algumas vezes".

Os itens das três seções do questionário que avaliaram o suporte à transferência de treinamento, mais especificamente os fatores situacionais de apoio, suporte material e consequências associadas ao uso de novas habilidades foram tabuladas para verificar qual é o item mais deficiente. De modo geral, as respostas da amostra para o suporte à transferência não foram consideradas completamente satisfatórias, oscilando entre 1, que correspondeu a “nunca" na escala Likert, e 5, correspondente a "sempre". Dessa forma, a média geral dos itens ficou em torno de 3 , correspondente a "algumas vezes", conforme descrito na Tabela 1.

Tabela 1 Estatística geral dos fatores de suporte à transferência.

\begin{tabular}{c|c|c|c}
\hline Estatísticas & \multicolumn{3}{|c}{ Fatores de suporte a transferência } \\
\hline $\begin{array}{c}\text { Fatores situacionais de } \\
\text { apoio }\end{array}$ & Suporte material & $\begin{array}{c}\text { Consequências associadas ao uso de } \\
\text { novas habilidades }\end{array}$ \\
\hline Média & 3,03 & 3,41 & 3,03 \\
\hline Desvio Padrão & 0,73 & 0,79 & 0,51 \\
\hline Amplitude & $1-5$ & $1-5$ & $1-5$ \\
\hline
\end{tabular}

Fonte: Dados da pesquisa.

Por meio de um estudo das freqüências, constataram-se as avaliações mais favoráveis ao Suporte à transferência de treinamento. Destacaram-se os altos índices de concordância dos participantes (mais de 50\%), com os itens "tenho oportunidades de utilizar no trabalho o que aprendi no curso", "meu chefe encoraja a aplicação", "os recursos materiais estão em boas condições de uso", "minhas sugestões são levadas em consideração" e "recebo apoio dos colegas experientes". Em contrapartida, verificou-se que um percentual de quase $50 \%$ dos servidores da amostra consultada não recebe advertências quando comete erros.

Para os "fatores situacionais de apoio", chama-se atenção especialmente para os itens que fazem referência à oportunidade de aplicar no trabalho o conhecimento adquirido no curso e à atuação do chefe imediato em encorajar a aplicação dos novos conhecimentos.

Constatou-se que a amostra planeja em conjunto com a chefia imediata o uso das novas habilidades apenas "algumas vezes". Esse resultado vai ao encontro dos achados de Abbad (1999), que indicaram que os chefes imediatos nunca ou raramente planejam com o servidor a aplicação das novas habilidades.

Os itens que receberam melhores avaliações correspondem à oportunidade de utilizar no trabalho o que aprenderam no curso e ao fato de a chefia encorajá-lo a aplicar o 
conhecimento adquirido. Alguns estudos indicam os fatores situacionais de apoio e consequências associadas ao uso das novas habilidades como sendo muito importantes na explicação do nível de impacto (BORGES-ANDRADE e ABBAD, 1996; ABBAD, 1999; ABBAD et al., 1999; SALAS e CANNON-BOWERS, 2001; LACERDA e ABBAD, 2003).

Os itens referentes ao "suporte material" foram avaliados de forma favorável, indicando que a organização oferece material para consecução das tarefas.

Em relação ao comprometimento afetivo, observa-se que $85 \%$ dos colaboradores apresentam uma união emocional que vai além da lealdade passiva, envolvendo também uma relação ativa na qual desejam dar algo de si para contribuir com uma ação relevante para os objetivos da empresa; $14 \%$ apresentam grau de comprometimento moderadamente positivo e um número insignificante dos colaboradores (1\%) apresentam baixo comprometimento afetivo.

No que se refere às afirmações do comprometimento instrumental, caracterizado pela percepção de que seria custoso interromper o curso da ação, em que colaboradores estruturam o comprometimento em função das recompensas (BECKER, 1969) e permanecem na organização porque precisam (BASTOS, 1994; COSTA, 2007), a grande maioria (63\% dos servidores) apresenta alto grau de comprometimento instrumental, 19\% expressam grau moderadamente positivo e apenas 18\% apresentam baixo comprometimento instrumental.

Em relação ao comprometimento normativo, observou-se que os servidores que apresentam alto comprometimento normativo permanecem na organização porque sentem obrigação de ficar (MEYER e ALLEN, 1993). É interessante observar que a internalização das normas como razão de permanência, o sentimento de obrigação, praticamente inexiste para $56 \%$ dos colaboradores; $28 \%$ expressam grau moderadamente positivo e $16 \%$ apresentam alto grau de comprometimento normativo.

Com base nos dados da Tabela 2, constata-se que o comprometimento afetivo predomina no grupo. Em seguida, aparece o vínculo instrumental. Os resultados demonstram que os servidores pesquisados contribuirão com maior vigor para a organização, resultando em menor turnover, baixo absenteísmo e maior produtividade. Já os indivíduos instrumentalmente comprometidos não farão mais que o mínimo necessário (REGO e SOUTO, 2004). 
Tabela 2 Estatística de Comprometimento Organizacional.

\begin{tabular}{l|c|c|c}
\hline \multicolumn{1}{c|}{ Estatísticas } & \multicolumn{3}{c}{ Comprometimento } \\
\hline Média & Afetivo & Instrumental & Normativo \\
\hline Desvio Padrão & 4,06 & 3,64 & 2,46 \\
\hline Amplitude & 0,64 & 1,08 & 1,00 \\
\hline
\end{tabular}

Fonte: Dados da pesquisa.

Os indivíduos instrumentalmente comprometidos enfatizam uma avaliação dos custos associados ao sair, envolvendo um cálculo de perdas e ganhos nas trocas que o indivíduo faz com a organização (BECKER, 1969).

Quanto ao Entrincheiramento Organizacional, a maioria absoluta da amostra (71\%) apresentou um Entrincheiramento moderado; 16\% apresentam um baixo entrincheiramento, ou seja, não verificam grandes custos associados a sua saída, ou podem acreditar que há custos, mas estão percebendo outras oportunidades de trabalho que sejam compensatórias. Ainda, 13\% da amostra demonstra um alto Entrincheiramento Organizacional, o que significa que, ao serem perguntados se deixariam a instituição, os servidores diriam que não a deixariam, pois não visualizam alternativas, ou não gostariam de perder determinados benefícios oferecidos pela instituição.

Após a análise de frequência do nível de entrincheiramento Organizacional, realizouse uma análise das frequências de cada um dos fatores de Entrincheiramento Organizacional em separado. Em relação ao fator “Ajustamento à Posição Social”, nota-se que a maior parte da amostra, quase a metade $(48 \%)$, considerou que não teriam problemas em se adaptar a novas condições de trabalho caso mudassem de organização; 34\% da amostra indicou um certo receio em relação aos ajustes que deveria fazer para ser reconhecido em outra organização, conhecer os processos organzacionais e as suas atribuições ao mudar de organização; e, $18 \%$ da amostra não deixaria a instituição, pois considera muito alto o investimento que teria que fazer para se adaptar às novas condições de trabalho e aos colegas.

Aproximadamente $33 \%$ da amostra possui grande dificuldade de visualizar outras oportunidades de emprego em outra organização, seja devido a percepções de restrições de mercado ou até mesmo em relação a sua especificidade do perfil profissional, o que poderia não ser aceito por outras organizações; $18 \%$ dos indivíduos sairiam sem problemas da organização, pois acreditam que teriam oportunidades de emprego em outras organizações caso saíssem da UFSM; e, a grande maioria (77\%) sugere que possui moderadas restrições no 
mercado de trabalho, moderados déficits em seu perfil profissional ao considerar sua idade ou outros fatores que possam reduzir a sua empregabilidade percebida. Observa-se que o fator "limitação de alternativas" estaria ligado à percepção do sujeito sobre o seu potencial de recolocação no mercado (BAIOCCHI e MAGALHAES, 2004).

No que tange ao nível atingido em relação aos "Arranjos Burocráticos Impessoais", os achados indicam que 52\% (mais da metade da amostra) não deixariam a UFSM, pois acreditam que estariam perdendo sua estabilidade financeira ou outros benefícios concedidos pela instituição, tais como: férias, feriados pagos, aposentadoria, entre outros. Outra parcela significativa da amostra (40\%) apresentou um índice moderado em relação a esse fator; e, por fim, $8 \%$ da amostra deixaria sem problemas a organização, pois aspectos como estabilidade financeira e outros benefícios não são fatores que os prendem à instituição.

Tabela 3 Estatística geral dos Fatores de Entrincheiramento Organizacional.

\begin{tabular}{l|c|c|c}
\hline \multicolumn{1}{|c|}{ Estatísticas } & \multicolumn{3}{|c}{ Fatores de Entrincheiramento } \\
\hline Média & $\begin{array}{c}\text { Ajustamento à } \\
\text { posição social }\end{array}$ & $\begin{array}{c}\text { Limitação de } \\
\text { alternativas }\end{array}$ & $\begin{array}{c}\text { Arranjos Burocráticos } \\
\text { Impessoais }\end{array}$ \\
\hline Desvio Padrão & 2,67 & 2,88 & 3,53 \\
\hline Amplitude & 0,94 & 0,49 & 0,84 \\
\hline
\end{tabular}

Fonte: Dados da pesquisa.

A Tabela 3 resume por meio das médias, pelo desvio-padrão e pela amplitude as diferenças entre os fatores. Dessa forma, nota-se que o fator "Arranjos Burocráticos Impessoais" se destacou com uma média de 3,53, seguido dos fatores "Limitações de alternativas", com média igual a 2,88, e "Ajustamento a posição Social”, com média 2,67. Contudo, as diferenças não foram significativas. Os índices obtidos pela amostra para todos os fatores de entrincheiramento foram moderados, exceto o fator arranjos burocráticos impessoais, que foi alto. A partir dos desvios-padrão dos três fatores, pode-se notar que não houve grandes divergências entre as respostas dos participantes da pesquisa.

\section{CONSIDERAÇÕES FINAIS}

Os objetivos propostos neste estudo foram atingidos. Quanto ao nível obtido pelos pesquisados em cada variável, pode-se notar que em relação ao Impacto do Treinamento no Trabalho, medido em amplitude, que o resultado foi positivo. Verificou-se um alto impacto do treinamento no trabalho por parte dos servidores, com uma média de 3,87. Esse resultado 
demonstra que é importante incentivar os indivíduos a se especializarem, visto que os mesmos estão transferindo para o setor de trabalho o conhecimento adquirido durante os cursos.

Quando se observa os itens melhor avaliados, percebe-se que, ao investir nas ações de qualificação e capacitação, a organização deixa seus funcionários mais autoconfiantes e motivados. O fato de que, neste estudo em específico, os participantes da pesquisa não terem diminuído o número de erros cometidos no setor de trabalho pode estar associado à estandardização dos processos e atrelamento às normas dentro do contexto público.

Observando-se os índices de Suporte à Transferência conclui-se que "algumas vezes" existe Suporte à Transferência considerado como sendo satisfatório pela amostra. Esse dado exige maior esforço por parte da organização estudada, pois, de acordo com Abbad (1999), o impacto depende muito de um ambiente organizacional propício ao uso de novas habilidades. Os chefes e colegas devem apoiar o egresso ao uso de novas habilidades, e ainda devem ser garantidas condições materiais suficientes e de qualidade necessários à transferência do conhecimento.

Se a organização não atender a esses itens, corre o sério risco de não manter o índice obtido para o impacto do treinamento no trabalho por um longo período de tempo. Isso porque os cursos sozinhos não são capazes de garantir impacto positivo e duradouro no desempenho da pessoa, sendo necessária a adoção de estratégias de gestão pós-qualificação. O Suporte à Transferência é um componente crítico, uma vez que as pessoas não são capazes de aplicar no cargo as habilidades aprendidas no treinamento se não contarem com um clima de apoio ao uso dos comportamentos aprendidos no treinamento (ABBAD e SALLORENZO, 2001).

Os itens pior avaliados indicam que existe muito a ser feito para aumentar a participação ativa das chefias, planejando em conjunto com os egressos o uso das novas habilidades, bem como chamando sua atenção quando cometem erros. Outro item, mal avaliado, demonstra a necessidade da instituição fornecer recursos materiais extras para a aplicação das novas habilidades.

Em relação ao Comprometimento Organizacional, os dados obtidos indicam que a maior parte dos colaboradores está disposta a exercer esforço em benefício da instituição pesquisada. Além do Comprometimento Organizacional como um todo, foram analisados os três fatores do construto: Comprometimento afetivo, instrumental e normativo separadamente. Grande parte da amostra pesquisada apresentou um vínculo emocional que vai além da 
lealdade passiva, envolvendo também uma relação ativa na qual desejam dar algo de si para contribuir com uma ação relevante para os objetivos da instituição. Observa-se que esse vínculo é benéfico tanto para a organização como para o empregado comprometido, pois o conceito de comprometimento organizacional está ligado ao bem estar no trabalho e com a satisfação com o mesmo (FERRAZ e SIQUEIRA, 2006). Pelo nível de Comprometimento relatado pelos participantes, a organização deverá ter um baixo absenteísmo e rotatividade, de acordo com estudo de Siqueira e Gomide Jr., 2004. E, ainda, terá funcionários dispostos a atingir os objetivos organizacionais (MULLER et al., 2005). Os funcionários se dedicarão e apoiarão a organização independentemente de recompensas. Eles se esforçarão mesmo diante da inexistência de possibilidades de promoções e benefícios (BROW, 1996; COSTA, 2007). Esses dados são contrários à imagem atribuída ao servidor público pela sociedade.

De acordo com Moraes, Marques e Correia (1998), tem sido atribuída ao servidor público uma imagem de "ineficiência decorrente de um excessivo aparato burocrático e o baixo engajamento de seus dirigentes e servidores com o propósito maior dessas mesmas organizações” (MORAES, MARQUES e CORREIA, 1998, p.2). De acordo com os níveis de comprometimento obtido na amostra, esses indivíduos não pouparão esforços para alcançar as metas organizacionais.

Ainda com base nos resultados, percebe-se que a instituição tem um imenso significado para os servidores, pois eles se interessam pelo destino da organização e sentemse orgulhosos em revelar às pessoas que são parte da instituição em que trabalham.

A maioria absoluta da amostra (71\%) apresentou um Entrincheiramento moderado; $16 \%$ apresentam um baixo entrincheiramento, ou seja, não verificam grandes custos associados a sua saída, ou podem acreditar que há custos, mas estão percebendo outras oportunidades de trabalho que sejam compensatórias. Ainda, ao ser questionada se deixaria a instituição, $13 \%$ da amostra respondeu que não, pois não visualiza alternativas, ou não gostaria de perder determinados benefícios oferecidos pela instituição.

É importante enfatizar que os extremos de entrincheiramento (excessiva mobilidade versus mobilidade muito baixa) não são interessantes para a empresa. Isso porque a alta mobilidade afeta a aprendizagem organizacional e, como consequência, a competitividade da organização, a perda da memória da organização, elevados custos para gerenciar os trabalhadores e burnout dos empregados. De outra banda, os indivíduos muito entrincheirados apresentam baixo nível de motivação e habilidades/conhecimentos ultrapassados, o que 
também não é de valia nem para a instituição, nem para o profissional (CARSON e CARSON, 1997).

O maior medo de deixar a organização estaria ligado às perdas de vantagens financeiras e à estabilidade. A grande permanência dos servidores nessa instituição deve-se à estabilidade. Esse fato pode estar atrelado ao contrato de trabalho estatutário (Regime Jurídico Único), que garante estabilidade ao servidor após três anos de efetivo exercício. Findo tal período, o servidor só poderá ser exonerado por meio de processo administrativo próprio destinado para tal fim, no qual é assegurada a ampla defesa ao servidor público.

Destarte, o servidor acredita possuir oportunidades de emprego fora da instituição. Sob outra perspectiva, os servidores não se sentem totalmente presos por falta de alternativas. Eles acreditam que, por vezes, conseguiriam colocação no mercado de trabalho, se adaptariam a novos postos e não estariam jogando totalmente fora seu esforço e dedicação para com a instituição.

A grande maioria sugere que possui moderadas restrições no mercado de trabalho, moderados déficits em seu perfil profissional ao considerar sua idade ou outros fatores que possam reduzir a sua empregabilidade percebida. Os servidores da UFSM não deixariam a instituição, pois acreditam que estariam perdendo sua estabilidade financeira ou outros benefícios concedidos pela mesma, tais como: férias, feriados pagos, aposentadoria, entre outros.

Vale ressaltar que, sendo um estudo de caso, a discussão está limitada ao contexto da organização estudada. Outro hiato deixado pelo presente estudo foi a ausência de heteroavaliações (com os colegas de trabalho dos egressos e com a sua chefia imediata), as quais, se tivessem ocorrido, teriam garantido maior confiabilidade aos resultados. Sugere-se assim, estudos futuros que venham a suprir essas lacunas, bem como estudos que comparem as variáveis aqui estudadas antes e após os cursos.

\section{REFERENCIAS}

ABBAD, G.; BORGES-ANDRADE, J. E. Aprendizagem humana em organizações de trabalho. In: ZANELLI, J. C.; BORGES-ANDRADE, J. E.; BASTOS, A. V. B. (Org.). Psicologia, organizações e trabalho no Brasil. Porto Alegre: Artmed, p. 237-275, 2004.

ABBAD, G.; SALLORENZO, L. H. Desenvolvimento e validação de escalas de suporte à transferência de treinamento. Revista de Administração, São Paulo, v. 36, n.2, p.33-45, 2001. 
ABBAD, G. Um modelo de Avaliação do Impacto do treinamento no trabalho IMPACT. 1999. Tese (Doutorado em Psicologia) - Instituto de Psicologia. Universidade Federal de Brasília, Brasília: 1999.

ABBAD, G; PILATI, R; BORGES-ANDRADE, J. Percepção de Suporte Organizacional: Desenvolvimento e Validação de um Questionário. Revista de Administração Contemporânea, v. 3, n. 2, p. 29-51, 1999.

ALVES, A.R; TAMAYO, A. Sistema de avaliação do treinamento da Telebrás - SAT. Revista de Administração. São Paulo v. 28, n. 4, p. 73-80, out/dez, 1993.

BAIOCCHI, A.; MAGALHÃES, M. Relações entre processos de comprometimento, entrincheiramento e motivação vital em carreiras profissionais. Revista Brasileira de Orientação Profissional, v. 5, n. 1, p. 63-71, 2004.

BASTOS, A. V. B.; RODRIGUES, A. C. A.; MOSCON, D. C. B.; COSTA e SILVA, E. E.; PINHO, A. P. M. Comprometimento no trabalho: fundamentos para a gestão de pessoas. In: BORGES, L. O.; MOURÃO, L. O trabalho e as organizações: atuações a partir da psicologia. Artmed: 2013, p. 279-310.

BASTOS, A. V. B. Comprometimento, consentimento ou entrincheiramento? Um estudo comparativo entre categorias ocupacionais e contextos organizacionais. Relatório final apresentado ao CNPQ. Bahia: Salvador, 2009.

BASTOS, A. V. B.; SIQUEIRA, M. M. M; MEDEIROS, C. A. F; MENEZES, I. G. Comprometimento Organizacional. In: SIQUEIRA, M. M. M. (Org.) Medidas do comprometimento organizacional: ferramentas de diagnóstico e de gestão. Porto Alegre: Artmed, p. 49-95, 2008.

Bastos, A. V. B. Comprometimento no trabalho: a estrutura dos vínculos do trabalhador com a organização, a carreira e o sindicato. 1994. Tese (Doutorado em Psicologia) - Instituto de Psicologia da Universidade de Brasília, Brasília, DF, 1994.

Becker, H. S. Notes on the concept of commitment. The American Journal of Sociology, v. 66, n. 1, p. 32-40, 1960.

BORGES-ANDRADE, J. E.; ABBAD, G. Treinamento no Brasil : reflexões sobre suas pesquisas. Revista de Administração, v. 31, n. 2, p. 112-125, 1996.

BRANDÃO, M. G. A.; BASTOS, A. V. B. Comprometimento organizacional em uma instituição universitária. Revista de Administração, v. 28, n. 3, p. 50-61, 1993.

BROW, R.B. Organizational commitment: clarifying the concept and simplifying the existing construct typology. Journal of Vocational Behavior, v. 49, n. 42, p.230-251, 1996.

CARSON, K. D.; CARSON, P. P. Career entrenchment: a quiet march toward occupational death? Academy Of Management Executive, v. 11, n. 1, p. 62-75, 1997. 
CARSON, K. D.; CARSON, P. P.; BEDEIAN, A. G. Development and construct of a career entrenchment measure. Journal of Occupational and Organizational Psychology, v. 6, p. 301-320, 1995.

COHEN, A. Multiple commitments in the workplace: an integrative approach. Lawrence Erlbaum Associates, Publishers. Mahwah, New Jersey, 2003.

COSTA, V. M. F. As bases afetiva e instrumental do comprometimento Organizacional: confrontando suas diferenças entre empresas e trabalhadores da agricultura irrigada do Pólo Juazeiro/Petrolina. Tese (Doutorado em Administração). Universidade Federal da Bahia, 2007.

FINGER, M; BRAND, S. Conceito de "Organização de Aprendizagem" aplicado à transformação do setor público: contribuições conceituais ao desenvolvimento da teoria. In: EASTERBY-SMITH, M. (Coord.); BURGOYNE, J. (Coord.); ARAUJO, L. (Coord.). Aprendizagem organizacional e organização de aprendizagem: desenvolvimento na teoria e na prática. São Paulo: Atlas, 2001, p.163-195.

Ferraz, C. R.; Siqueira, M. M. M. Bem-estar no trabalho: estudo com uma amostra de professores. Trabalho apresentado no IV GIBEST - Grupo Interinstitucional de Pesquisa Bem-Estar, Suporte e Trabalho. Uberlândia, MG, 2006.

GIL, A. C. Métodos e técnicas de pesquisa social. São Paulo: Atlas, 2010.

KLEIN, H. J.; MOLLOY, J. C.; BRINSFIELD, C. T. Reconceptualizing workplace commitment to redress a stretched construct: revisiting assumptions and removing confounds. Academy of Management Review, v. 37, n. 1, p. 130-151, 2012.

LACERDA, E. R. M; ABBAD, G. Impacto do treinamento no trabalho: investigando variáveis motivacionais e organizacionais como suas preditoras. Revista de Administração Contemporânea, v. 7, n. 4, p. 77-96, out/dez. 2003.

MEYER, J.P., ALLEN, N. J.; SMITH, C. A. Commitment to organizations and occupations: extension and test of a three-component conceptualization. Journal of Applied Psychology, v. 78, n. 4, p. 538-551, 1993.

MORAES, L. F. R.; MARQUES, A. L.; CORREIA, L. F. Comprometimento organizacional: uma contribuição ao constructo. In: ENCONTRO NACIONAL DOS PROGRAMAS DE PÓS GRADUAÇÃO EM ADMINISTRAÇÃO, 22, 1998, Foz do Iguaçu. Anais... Foz do Iguaçu: ANPAD, 1998.

MOWDAY, R. T; PORTER, L. W; STEERS, R. M. Employee organization linkages: the psychology of commitment absenteeism, and turnover. New York: Academic Press, 1982.

MOWDAY, R.T.; PORTER, L.W. e STEERS, R.M. The measurement of organizational commitment. Journal of Vocational Behavior, n. 14, p. 224-247, 1979. 
MULLER, M.; RAUSKI, E. F.; EYNG I. S.; MOREIRA, J. Comprometimento organizacional: um estudo de caso no supermercado "Beta". Revista Gestão Industrial, v. 4, n. 1, p. 511-518, 2005.

REGO, A.; SOUTO, S. A percepção de justiça como antecedente do comprometimento organizacional: um estudo luso-brasileiro. Revista de administração contemporânea, v. 1, n.8, p. 151-177, 2004.

RODRIGUES, A. C. de A.; BASTOS, A. V. B. Entrincheiramento Organizacional: Construção e Validação da Escala. Psicologia: Reflexão e Crítica, v. 25, n. 4, p. 688-700, 2012.

RODRIGUES, A. C. A. Do comprometimento de continuação ao entrincheiramento organizacional: o percurso de validação da escala e análise da sobreposição entre os construtos. Dissertação (Mestrado em Psicologia) - Universidade Federal da Bahia, Bahia, 2009.

ROWE, D. E. O.; BASTOS, A. V. B. Comprometimento ou Entrincheiramento na Carreira? Um Estudo Entre Docentes do Ensino Superior. In: ENCONTRO DA ANPAD, 32, Rio de janeiro. Anais... Rio de Janeiro: ANPAD, 2008.

SIQUEIRA, M.M.M.; GOMIDE Jr., S. Vínculos do indivíduo com a organização e com o trabalho. In: ZANELLI, J. C.; BORGES-ANDRADE, J. E. e BASTOS, A.V.B.(Orgs.)

Psicologia, organizações e trabalho. Porto Alegre/RS: Artmed, 2004, p. 300-328.

SALAS, E.; CANNON-BOWERS, J. A. The science of training: A decade of progress. Annual Review of Psychology, v. 52, p. 471-499, 2001.

TEIXEIRA, M. G. Comprometimento organizacional: uma análise dos fatores individuais numa empresa de prestação de serviços. In: REUNIÃO ANUAL DA ASSOCIAÇÃO NACIONAL DE PROGRAMAS DE PÓS-GRADUAÇÃO EM ADMINISTRAÇÃO, 18, v. 10, 1994, Curitiba, Anais... Florianópolis: ANPAD, 1994.

UFSM. UNIVERSIDADE FEDERAL DE SANTA MARIA. UFSM em números 2009. Santa Maria: [s.n.], 2009. 17p. 